\title{
Vinyl Polymerization. CDVII. Polymerization of Methyl Methacrylate Initiated by Diphenyldisulfide and Cu(II) Ion
}

\author{
Tatsuro OUCHI, Nobuaki BEIKA, and Minoru IMOTO \\ Department of Applied Chemistry, Faculty of Engineering, \\ Kansai University, Senriyama, Suita, Osaka 564, Japan.
}

(Received September 24, 1981)

\begin{abstract}
Radical polymerization of methyl methacrylate (MMA) initiated by diphenyldisulfide (DPDS) and $\mathrm{CuCl}_{2}$ was carried out in a mixed solvent of 1,4-dioxane and water. The rate was expressed by the equation; $R_{\mathrm{p}}=k[\mathrm{DPDS}]^{0.4}[\mathrm{MMA}]^{1.5}$ and the overall activation energy was found to be $72.8 \mathrm{~kJ} \mathrm{~mol}^{-1}$. During the polymerization, the concentration of $\mathrm{Cu}(\mathrm{II})$ ion diminished. The initiation mechanism was discussed.

KEY WORDS Diphenyldisulfide / ESR of $\mathrm{Cu}(\mathrm{II})$ / Electrical Conductivity of $\mathrm{Cu}(\mathrm{II})$ / Redox Polymerization /
\end{abstract}

Formerly, we reported ${ }^{1}$ that lysozyme having four S-S linkages in a molecule could initiated the polymerization of methyl methacrylate (MMA) in an aqueous solution of $\mathrm{CuCl}_{2}$, and concluded that the initiation was consisted of three reactions, that is, (i) a normal "uncatalyzed polymerization" which is a reaction of polypeptide portion of lysozyme with $\mathrm{Cu}(\mathrm{II})$ ion, water and MMA, (ii) a generation of free radicals by the reaction of S-S bond with $\mathrm{Cu}(\mathrm{II})$ ion, and (iii) a thermal polymerization in MMA phase.

The extent of our research indicates that the generation of free radicals by the reaction of S-S bond with $\mathrm{Cu}(\mathrm{II})$ ion in the dark is not known. Accordingly, it is necessary to ascertain whether a simple compound having S-S bond can initiate a radical polymerization of MMA in the dark and in the presence of $\mathrm{Cu}(\mathrm{II})$ ion. The present paper deals with this kind of polymerization. As a simple disulfide model, diphenyldisulfide (DPDS) was used.

\section{EXPERIMENTAL}

\section{Reagent}

DPDS was recrystallized twice from methanol. $\mathrm{CuCl}_{2} \cdot 2 \mathrm{H}_{2} \mathrm{O}$ was of special commercial grade and used without further purification. MMA was pu- rified by the usual method. Water was ionexchanged and distilled. 1,4-Dioxane (DO) was freed from peroxidic impurities by passing a column filled with active alumina.

\section{Procedures}

Vinyl monomer and a solution of DPDS and $\mathrm{CuCl}_{2} \cdot 2 \mathrm{H}_{2} \mathrm{O}$ in a mixed solvent of $\mathrm{DO}$ and water $(7$ : 3 in volume) were placed in a tube and sealed under vacuum after thawing with nitrogen. After the reaction in the dark, the contents were poured into a large amount of methanol to precipitate the produced poly(MMA). The polymer was dried at $80^{\circ} \mathrm{C}$ under vacuum and weighed. The conversion of MMA was calculated by the following equation:

$$
\text { Conversion } / \%=\frac{\text { Wt of produced poly }(\mathrm{MMA})}{\text { Wt of feeded MMA }} \times 100
$$

Measurement of $\bar{P}_{n}$ : the number-average degree of polymerization of poly(MMA) was measured from the viscosity in benzene at $30^{\circ} \mathrm{C}$, using Welch's equation. $^{2}$

ESR spectrum: The spectrum was obtained by a Nippon Denshi ESR spectrometer (JFS-1X Type).

Electrical conductivity: The conductance was measured by a conductometer (Yanagimoto Co.) with two Pt-electrodes. 


\section{RESULTS AND DISCUSSION}

Effect of the Amount of $\mathrm{Cu}(\mathrm{II})$ Ion on the Polymerization

Into $10 \mathrm{~cm}^{3}$ of the mixed solvent, $0.1 \mathrm{~g}$ of DPDS and varied amounts of $\mathrm{CuCl}_{2} \cdot 2 \mathrm{H}_{2} \mathrm{O}$ were dissolved, and $3 \mathrm{~cm}^{3}$ of MMA were added. Since the solubility of MMA was not very large (the solubility of MMA at $24^{\circ} \mathrm{C}$ was $1.88 \mathrm{~g} / 10 \mathrm{~cm}^{3}$ of the mixed solvent), the polymerization system was apparently heterogeneous. The results for the conversion are shown in Figure 1.

It was confirmed that DPDS and $\mathrm{Cu}(\mathrm{II})$ ion could initiate the polymerization of MMA, even if the conversion remained low. When a large amount of $\mathrm{CuCl}_{2}$ was used, the conversion decreased. This was due to the inhibition by $\mathrm{Cu}(\mathrm{II})$ ion, according to the following reaction:

$$
\mathrm{R} \cdot+\mathrm{CuCl}_{2} \longrightarrow \mathrm{RCl}+\mathrm{CuCl}
$$

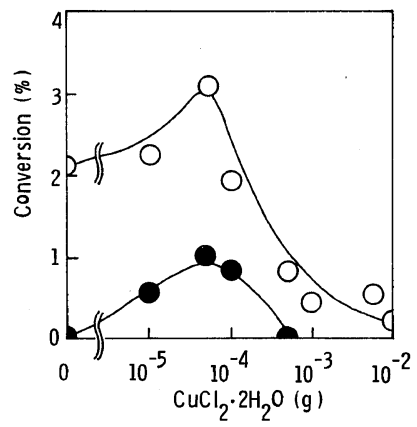

Figure 1. Effect of the amount of $\mathrm{CuCl}_{2} \cdot 2 \mathrm{H}_{2} \mathrm{O}$ on the conversion of MMA: MMA, $3 \mathrm{~cm}^{3} ; \mathrm{DO}, 7 \mathrm{~cm}^{3} ; \mathrm{H}_{2} \mathrm{O}$, $3 \mathrm{~cm}^{3}$; temp, $85^{\circ} \mathrm{C}$; time, $3 \mathrm{~h}$; DPDS, $0.1 \mathrm{~g} \mathrm{(O);} \mathrm{DPDS,}$ $0 \mathrm{~g}(\bigcirc)$.

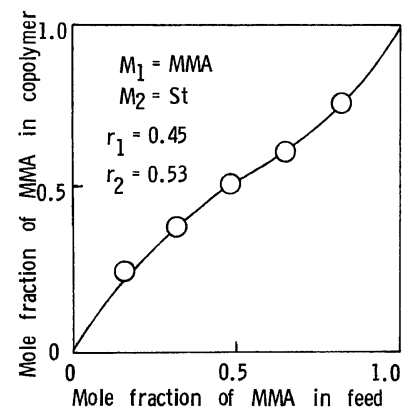

Figure 2. Composition curve of copolymer: (MMA + styrene), $3 \mathrm{~cm}^{3} ; \mathrm{CuCl}_{2} \cdot 2 \mathrm{H}_{2} \mathrm{O}, 5 \times 10^{-5} \mathrm{~g}$; DPDS, $0.1 \mathrm{~g}$; DO, $7 \mathrm{~cm}^{3} ; \mathrm{H}_{2} \mathrm{O}, 3 \mathrm{~cm}^{3}$; temp, $85^{\circ} \mathrm{C}$; time, $3 \mathrm{~h}$.
The present polymerization proceeds through a radical mechanism which is proved in the following section.

\section{Proof of the Radical Mechanism}

Two methods were applied: (1) Copolymerization of styrene with MMA was carried out, using the system of DPDS and $\mathrm{Cu}(\mathrm{II})$ ion in the mixed solvent. The results shown in Figure 2 verify that the polymerization proceeded through a radical mechanism. (2) Hydroquinone or diphenylpicrylhydrazil was added and these radical scavengers were found to inhibit the polymerization, as shown in Table I. Thus, it is proved that the polymerization proceeded through a radical mechanism.

\section{Time-Conversion Curve}

A time-conversion curve was obtained, as shown in Figure 3 and was not a straight line. However, it could be considered that during the first $3 \mathrm{~h}$, the conversion increased straightly. Also, in Figure 7 of the present paper, the same situation can be seen.

Table I. Effects of radical scavengers on the polymerization of $\mathrm{MMA}^{\mathrm{a}}$

\begin{tabular}{lcc}
\hline \multirow{2}{*}{ Radical scavenger } & $\mathrm{g}$ & Conversion \\
\cline { 3 - 3 } & & $\%$ \\
\hline None & 0.1 & 5.76 \\
$\begin{array}{l}\text { Hydroquinone } \\
\begin{array}{l}1,1-\text { Diphenyl-2- } \\
\text { picrylhydrazyl }\end{array}\end{array}$ & 0.1 & 0.62 \\
\hline
\end{tabular}

${ }^{a}$ MMA, $3 \mathrm{~cm}^{3}$, DPDS, $0.1 \mathrm{~g}, \mathrm{CuCl}_{2} \cdot 2 \mathrm{H}_{2} \mathrm{O}, 5 \times 10^{-5} \mathrm{~g}$; DO, $7 \mathrm{~cm}^{3} ; \mathrm{H}_{2} \mathrm{O}, 3 \mathrm{~cm}^{3}$; temp, $85^{\circ} \mathrm{C}$; time, $10 \mathrm{~h}$.

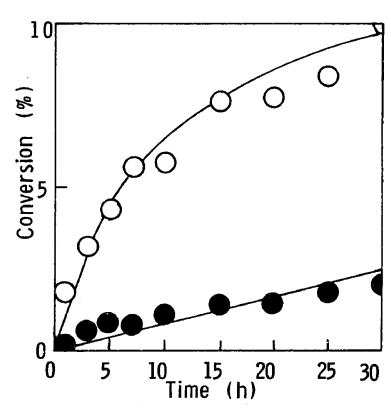

Figure 3. Time-conversion curves: MMA, $3 \mathrm{~cm}^{3}$; $\mathrm{CuCl}_{2} \cdot 2 \mathrm{H}_{2} \mathrm{O}, 5 \times 10^{-5} \mathrm{~g}$; DO, $7 \mathrm{~cm}^{3} ; \mathrm{H}_{2} \mathrm{O} 3 \mathrm{~cm}^{3}$; temp, $85^{\circ} \mathrm{C}$; DPDS, $0.1 \mathrm{~g}(\bigcirc)$; DPDS, $0 \mathrm{~g}(\bullet)$. 
There was no induction period. Therefore, the rate of polymerization, $R_{\mathrm{p}}$, may be obtained by dividing the conversion that occurred within the first $3 \mathrm{~h}$ by the polymerization time.

The corrected $R_{\mathrm{p}}$ was calculated by using eq 2 .

$$
R_{\mathrm{p}}(\text { corrected })=R_{\mathrm{p}}(\text { overall })-R_{\mathrm{p}}(\text { thermal })
$$

$R_{\mathrm{p}}$ (overall) and $R_{\mathrm{p}}$ (thermal) indicate the conversions of MMA in the presence and the absence of DPDS, respectively.

\section{Effect of the Amount of DPDS on Polymerization}

Figure 4 shows the effects of the amount of DPDS on the conversion of MMA and $\bar{P}_{n}$ of the produced poly(MMA). The conversion increased with the amount of DPDS, while $\bar{P}_{n}$ decreased rapidly. The rapid decrease in $\bar{P}_{n}$ suggests that DPDS was effective as a radical chain transfer reagent. The apparent chain transfer constant to DPDS, $C_{\mathrm{l}}$, was calculated according to the following equation.

$$
\frac{1}{\bar{P}_{n}}=\frac{1}{\bar{P}_{n 0}}+\mathrm{C}_{1} \frac{\text { [DPDS }]}{\text { [MMA] }}
$$

[MMA] in water was assumed to be constant at 1.55 mol dm${ }^{-3}$. The value of $C_{\mathrm{I}}$ was calculated to be $2.02 \times 10^{-3}$.

Effect of the Amount of MMA on the Polymerization

As mentioned above, MMA dissolved only partly in the mixed solvent. Nevertheless, an apparent relationship between the conversion of MMA and the fed amount of MMA is a matter warranting attention. The kinetics of such a heterogeneous

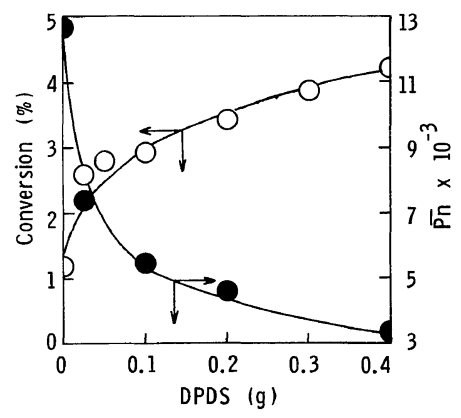

Figure 4. Effect of the amount of DPDS on the conversion and $\bar{P}_{n}$ of poly(MMA): MMA, $3 \mathrm{~cm}^{3} ; \mathrm{CuCl}_{2}$. $2 \mathrm{H}_{2} \mathrm{O}, 5 \times 10^{-5} \mathrm{~g}$; DO, $7 \mathrm{~cm}^{3} ; \mathrm{H}_{2} \mathrm{O}, 3 \mathrm{~cm}^{3}$; temp, $85^{\circ} \mathrm{C}$; time, $3 \mathrm{~h}$. polymerization has already been discussed by the present authors in the case of so-called "uncatalyzed polymerization." ${ }^{3,4}$ The results obtained are shown in Figure 4. The open and black circles incidate the conversion of MMA in the presence and absence of DPDS, respectively.

The corrected $R_{\mathrm{p}}$ in $\mathrm{g} \mathrm{h}^{-1}$ are coordinated with the amounts of MMA and DPDS. The results were shown in Figure 5.

From the slopes of the straight lines, the approximate eq 4 is introduced as,

$$
R_{\mathrm{p}}=k[\mathrm{MMA}]^{1.5}[\mathrm{DPDS}]^{0.4}
$$

\section{Measurement of Overall Activation Energy}

The polymerizations of MMA were carried out at $70-80^{\circ} \mathrm{C}$. Figure 7(a) and Figure 7(b) show the results for the presence and absence of DPDS, respectively. Using eq 2 , the corrected $R_{\mathrm{p}}$ were calculated, and applied to Arrhenius equation. As

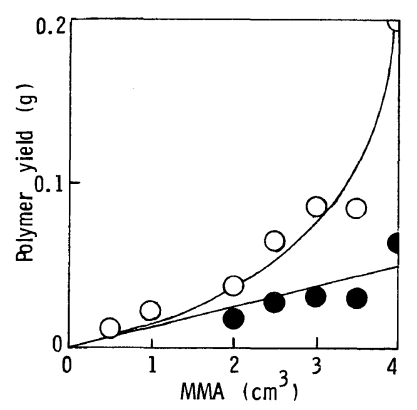

Figure 5. Effect of the amount of MMA on the polymer yield: $\mathrm{CuCl}_{2} \cdot 2 \mathrm{H}_{2} \mathrm{O}, 5 \times 10^{-5} \mathrm{~g} ; \mathrm{DO}, 7 \mathrm{~cm}^{3}$; $\mathrm{H}_{2} \mathrm{O}, 3 \mathrm{~cm}^{3}$; temp, $85^{\circ} \mathrm{C}$; time, $3 \mathrm{~h}$; DPDS, $0.1 \mathrm{~g}(\mathrm{O})$; DPDS, $0 \mathrm{~g}(\odot)$.

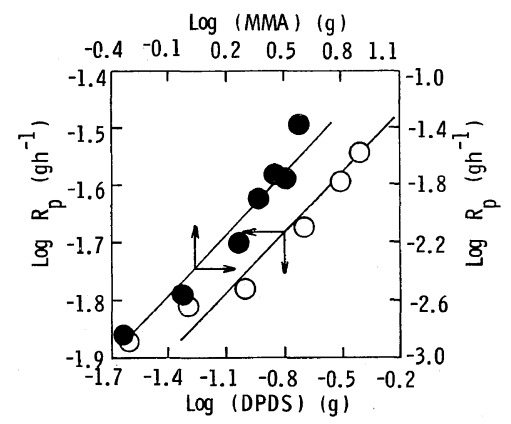

Figure 6. Plots of $\log R_{\mathrm{p}}$ vs. $\log$ (DPDS) or $\log$ (MMA): $\mathrm{CuCl}_{2} \cdot 2 \mathrm{H}_{2} \mathrm{O}, 5 \times 10^{-5} \mathrm{~g} ; \mathrm{DO}, 7 \mathrm{~cm}^{3} ; \mathrm{H}_{2} \mathrm{O}$, $3 \mathrm{~cm}^{3}$; temp, $85^{\circ} \mathrm{C}$; MMA, $3 \mathrm{~cm}^{3}$ (O); DPDS, $0.1 \mathrm{~g}\left(\mathrm{O}^{\circ}\right.$. 

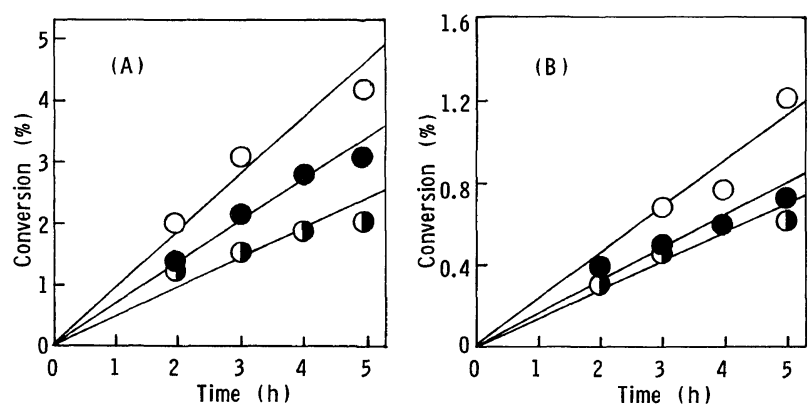

Figure 7. Time-conversion curves at $70-80^{\circ} \mathrm{C}: \mathrm{MMA}, 3 \mathrm{~cm}^{3} ; \mathrm{CuCl}_{2} \cdot 2 \mathrm{H}_{2} \mathrm{O}, 5 \times 10^{-5} \mathrm{~g}, \mathrm{DO}, 7 \mathrm{~cm}^{3} ; \mathrm{H}_{2} \mathrm{O}$, $3 \mathrm{~cm}^{3} ; \quad-70^{\circ} \mathrm{C} ;-75^{\circ} \mathrm{C} ; \mathrm{O}, 80^{\circ} \mathrm{C}$. (A), polymerization in the presence of $0.1 \mathrm{~g}$ of DPDS. (B), polymerization in the absence of DPDS.

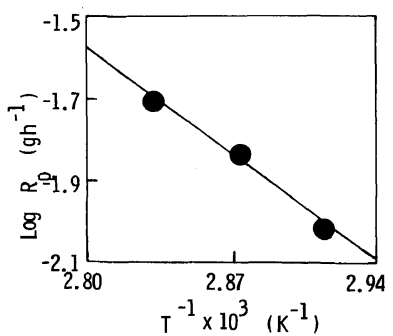

Figure 8. Application of Arrhenius equation.

Table II. Polymerizations of various vinyl monomers with DPDS ${ }^{\mathrm{a}}$

\begin{tabular}{lrrrrr}
\hline DPDS & \multicolumn{5}{c}{ Conversion/\% } \\
\hline \multicolumn{1}{c}{ g } & MMA & EMA & $n$-BMA & St & AN \\
\hline 0 & 1.20 & 4.39 & 7.46 & 3.12 & 0.36 \\
0.1 & 5.76 & 12.09 & 9.11 & 4.25 & 0.50 \\
\hline
\end{tabular}

a Monomer, $3 \mathrm{~cm}^{3} ; \mathrm{CuCl}_{2} \cdot 2 \mathrm{H}_{2} \mathrm{O}, 5 \times 10^{-5} \mathrm{~g} ; \mathrm{DO}, 7 \mathrm{~cm}^{3}$; $\mathrm{H}_{2} \mathrm{O}, 3 \mathrm{~cm}^{3}$; temp, $85^{\circ} \mathrm{C}$; time, $10 \mathrm{~h}$.

Figure 8 shows, a straight -ine was obtained. The calculated overall activation energy, $E_{\mathrm{a}}$, was 72.8 $\mathrm{kJ} \mathrm{mol}^{-1}$.

\section{Selectivity of Vinyl Monomer for Polymerization}

Vinyl monomers other than MMA were applied to the polymerization initiated by DPDS and $\mathrm{Cu}(\mathrm{II})$ ion and the results shown in Table II were obtained.

Ethyl methacrylate (EMA) was the most easily polymerizable monomer. The order of ease of polymerization is as follows: EMA $>$ MMA $>n$-butyl methacrylate $(n$-BMA) $>$ styrene $(\mathrm{St})>$ acryloni-

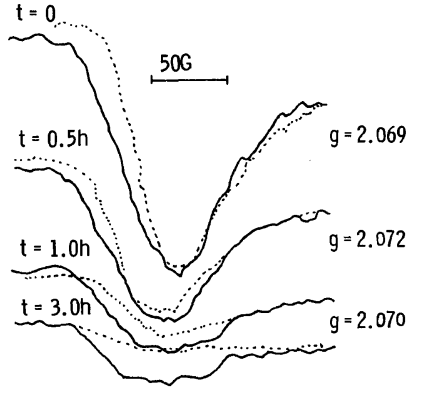

Figure 9. ESR spectra of the polymerization system $\left(-60^{\circ} \mathrm{C}\right)$. The conditions were shown in text: ---, [MMA] $1.55 \mathrm{~mol} \mathrm{dm}^{-3} ;-,[\mathrm{MMA}]$ none.

trile (AN).

\section{ESR Spectrum of the Reaction System}

A change in the ESR spectrum of the reaction system with time was observed. The conditions under which measurement of the spectrum was made are as follows: a solution of DPDS and $\mathrm{CuCl}_{2} \cdot 2 \mathrm{H}_{2} \mathrm{O}$ in the mixed solvent mentioned above was prepared. The concentrations of DPDS and $\mathrm{Cu}(\mathrm{II})$ ion were $0.55 \times 10^{-2} \mathrm{~mol} \mathrm{dm}^{-3}$ and $9.62 \times$ $10^{-2} \mathrm{~mol} \mathrm{dm}^{-3}$, respectively. The solution was heated at $85^{\circ} \mathrm{C}$ for various periods time, $t$, of with shaking, in the absence and the presence of MMA, whose concentrations were 0.0 and $1.55 \mathrm{~mol}$ $\mathrm{dm}^{-3}$. After a definite time, the solution was cooled to $-60^{\circ} \mathrm{C}$ and placed in the ESR apparatus.

Figure 9 shows the results obtained. Clearly it may be concluded that the concentration of $\mathrm{Cu}(\mathrm{II})$ decreases rapidly with time, regardless of the presence or absence of MMA. 

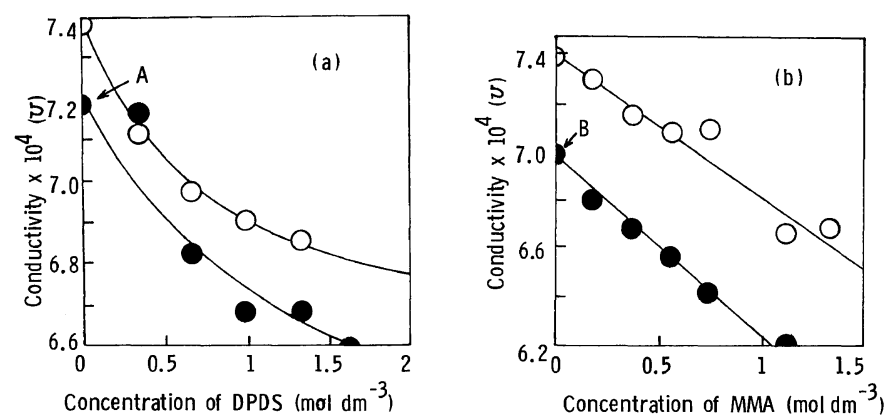

Figure 10. Electrical conductivity of $\mathrm{CuCl}_{2}$ in dioxane-water solution at $23^{\circ} \mathrm{C}$. (a) Electrical conductivity of $\mathrm{Cu}(\mathrm{II})$ ion vs. the concentration of DPDS in the absence $(\bigcirc)$ and the presence $(O)$ of MMA: (O): $\left[\mathrm{CuCl}_{2} \cdot 2 \mathrm{H}_{2} \mathrm{O}\right]=2.49 \times 10^{-2} \mathrm{~mol} \mathrm{dm}{ }^{-3} ;(\bigcirc):\left[\mathrm{CuCl}_{2} \cdot 2 \mathrm{H}_{2} \mathrm{O}\right]=2.49 \times 10^{-2} \mathrm{~mol} \mathrm{dm}^{-3}$, [MMA] $=$ $3.76 \times 10^{-1} \mathrm{~mol} \mathrm{dm}^{-3}$. (b) Electrical conductivity of $\mathrm{Cu}(\mathrm{II})$ ion $v s$. the concentration of MMA in the absence $(O)$ and the presence $(O)$ of DPDS; $(\bigcirc):\left[\mathrm{CuCl}_{2} \cdot 2 \mathrm{H}_{2} \mathrm{O}\right]=2.49 \times 10^{-2} \mathrm{~mol} \mathrm{dm}^{-3} ;(\mathbf{O}):\left[\mathrm{CuCl}_{2}\right.$. $\left.2 \mathrm{H}_{2} \mathrm{O}\right]=2.49 \times 10^{-2} \mathrm{~mol} \mathrm{dm}^{-3},[D P D S]=1.00 \times 10^{-2} \mathrm{~mol} \mathrm{dm}^{-3}$.

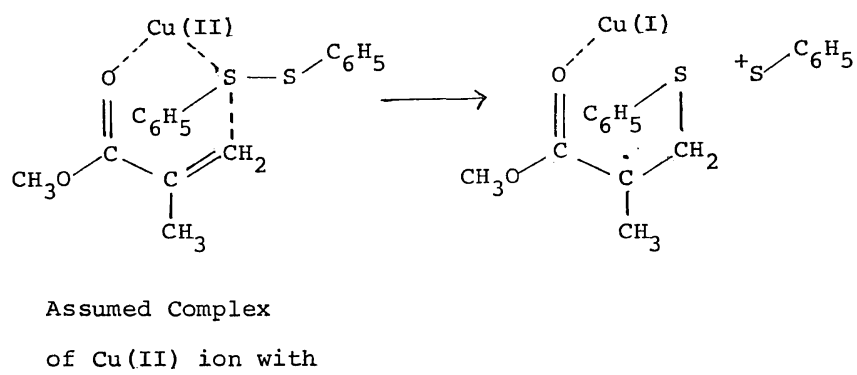

MMA and DPDS

Scheme I.
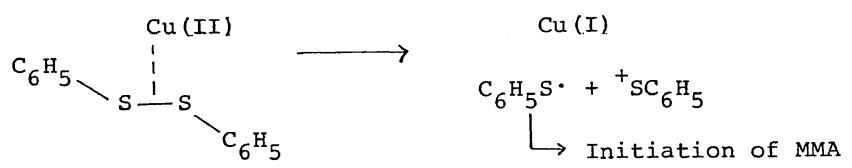

Scheme II.

Electrical Conductivity of the Reaction System

In order to confirm the formation of a complex of DPDS and MMA with $\mathrm{Cu}(\mathrm{II})$ ion, the electrical conductivity of the reaction system was measured. The solution of $\mathrm{CuCl}_{2}$, DPDS and/or MMA in the mixed solvent was allowed to stand for $20 \mathrm{~h}$ at room temperature. The conductance of the solution was measured at $23^{\circ} \mathrm{C}$. The results obtained are shown in Figures 10(a) and 10(b).

Points $\mathrm{A}$ and $\mathrm{B}$ show the decrease in the conductivity of $\mathrm{Cu}$ (II) ion, duing to the addition of MMA and DPDS. This decrease verifies the capture of $\mathrm{Cu}(\mathrm{II})$ ions by either MMA [Figure 10(a)] or
DPDS [Figure 10(b)]. Also the conductivity of a solution of $\mathrm{Cu}$ (II) ions and MMA or a solution of $\mathrm{Cu}(\mathrm{II})$ ions and DPDS decreases with the addition of DPDS or MMA. Therefore it may be assumed that $\mathrm{Cu}(\mathrm{II})$ ions formed a ternary complex with MMA and DPDS.

\section{Mechanism of Initiation}

From the results obtained above, following two initiation mechanisms were concluded to be operative:

Both mechanisms are applicable. However, from the standpoint of eq 4, Scheme I may be preferred. 
T. OUCHI, N. BeIKA, and M. Iмото

\section{REFERENCES}

1. T. Ouchi, T. Yoshikawa, and M. Imoto, J. Macromol. Sci., Chem., A12, 1523 (1978).

2. F. J. Welch, J. Polym. Sci., 61, 243 (1962).
3. M. Imoto, M. Sakae, and T. Ouchi, Makromol. Chem., 180, 2819 (1979).

4. M. Imoto, T. Ouchi, and E. Morita, Nippon Kagaku Kaishi, 1540 (1979). 